\title{
Mango Yield Mapping at the Orchard Scale Based on Tree Structure and Land Cover Assessed by UAV
}

\author{
Julien Sarron 1,2,3 Éric Malézieux ${ }^{1,2}$, Cheikh Amet Bassirou Sané ${ }^{4}$ and Émile Faye ${ }^{1,2,3, *}$ \\ 1 CIRAD, UPR HortSys, F-34398 Montpellier, France; julien.sarron@cirad.fr (J.S.); \\ eric.malezieux@cirad.fr (É.M.) \\ 2 HortSys, University Montpellier, CIRAD, F-34090 Montpellier, France \\ 3 Centre pour le Développement de l'Horticulture, ISRA, Dakar 14000, Senegal \\ 4 Université Cheikh Anta Diop (UCAD), Fac. Sci. Tech., Dakar BP 5005, Senegal; \\ cheikh84amet.bass@gmail.com \\ * Correspondence: emile.faye@cirad.fr
}

Received: 23 October 2018; Accepted: 26 November 2018; Published: 28 November 2018

check for updates

\begin{abstract}
In the value chain, yields are key information for both growers and other stakeholders in market supply and exports. However, orchard yields are often still based on an extrapolation of tree production which is visually assessed on a limited number of trees; a tedious and inaccurate task that gives no yield information at a finer scale than the orchard plot. In this work, we propose a method to accurately map individual tree production at the orchard scale by developing a trade-off methodology between mechanistic yield modelling and extensive fruit counting using machine vision systems. A methodological toolbox was developed and tested to estimate and map tree species, structure, and yields in mango orchards of various cropping systems (from monocultivar to plurispecific orchards) in the Niayes region, West Senegal. Tree structure parameters (height, crown area and volume), species, and mango cultivars were measured using unmanned aerial vehicle (UAV) photogrammetry and geographic, object-based image analysis. This procedure reached an average overall accuracy of 0.89 for classifying tree species and mango cultivars. Tree structure parameters combined with a fruit load index, which takes into account year and management effects, were implemented in predictive production models of three mango cultivars. Models reached satisfying accuracies with $\mathrm{R}^{2}$ greater than 0.77 and RMSE $\%$ ranging from $20 \%$ to $29 \%$ when evaluated with the measured production of 60 validation trees. In 2017, this methodology was applied to 15 orchards overflown by UAV, and estimated yields were compared to those measured by the growers for six of them, showing the proper efficiency of our technology. The proposed method achieved the breakthrough of rapidly and precisely mapping mango yields without detecting fruits from ground imagery, but rather, by linking yields with tree structural parameters. Such a tool will provide growers with accurate yield estimations at the orchard scale, and will permit them to study the parameters that drive yield heterogeneity within and between orchards.
\end{abstract}

Keywords: unmanned aerial vehicle; mango orchard; yield estimation; fruit detection; tree architecture; random forest; GEOBIA; structure-from-motion

\section{Introduction}

Mango (Mangifera indica L.) is a major fruit crop of the tropics and sub-tropics that guarantees the incomes and food security for local populations [1]. In West Africa, to meet an ever-increasing fruit demand from local and international markets [2], various mango cropping systems co-exist, from small, family-based, diversified orchards to large, commercial-based, monospecific orchards [3,4]. In this region, more than 20 polyembryonic and monoembryonic cultivars were featured by Rey et al. [4]. 
However, the lack of accurate and appropriate measurement practices of horticultural production is still hampering the development of the mango sector, resulting in poor data reliability in this region [5]. Mango yield, defined here as the production per unit of area (e.g., $\mathrm{t} \cdot \mathrm{ha}^{-1}$ ), estimated as early as possible before harvest, is a key to informing growers about cropping practices in order to enable them to address the physiological needs of each tree (pruning, watering, etc.) and to plan orchard management (harvest, packing, etc.), but also to advise regional agricultural policies [5]. At present, mango yield estimation is still based on the visual inspection of a limited number of trees on which fruits are manually counted, which is a tedious and time-consuming method that relies on the observer reliability and accuracy [6]. Yield estimation on the orchard scale then results from the multiplication of the average fruit number per sampled tree with the orchard tree density (i.e., number of trees per unit of area). Depending on the growers, this estimation is undertaken between two months and two weeks before harvest. At harvest time, orchard production is measured by counting the number of harvested fruit buckets and multiplying it by an average weight. Moreover, these inaccurate assessments of yield and production are mostly conducted in commercial and homogeneous orchard plots, and rarely in small, diversified orchards. Both methods provide low accuracy and give no yield information at a finer scale than the orchard plot (i.e., plot portion or tree scale), that sometimes exceeds 10 hectares. Whereas yield data may be accessible in commercial orchards with a quantifiable level of error, little and often no information is available in family-based orchards were harvest tasks are mostly performed by tradespeople. Additionally, in West Africa other, orchard characteristics such as acreage and planting density are unknown by the growers, or at best, are only roughly estimated. Hence, one of the underlying factors that explains the poor quality of data available is the lack of accurate and effective tools to estimate production and, to a larger extent, measure other orchard characteristics (acreage, planting density, etc.) [5]. In the meantime, providing growers with accurate yield maps will inform them about precise farming management, and will also help researchers to study the parameters driving yield heterogeneity within and between orchards [6,7].

One way to estimate yield in the field is to use crop models that evaluate plant yield responses to its genotype, environment, and cropping system [8]. However, models of tree crops are sparse, and there is currently no complete mango crop model forecasting production [9]. Indeed, mango trees are characterized by strong vegetative and reproductive asynchronisms and irregular bearings explained by interplays between several endogenous (cultivar, temporal phenology, etc.) and exogenous (climate, soil, agricultural practices, etc.) factors [10]. For instance, the relationship between flowering and the number of fruits remains unclear, and the effects of cultivars and previous growing cycles on this relationship has been evidenced [10]. These features hamper the development of a mechanistic model to estimate mango tree production, and compel growers to measure yield empirically.

Another way to estimate orchard yields is to measure individual tree production (e.g., $\mathrm{kg}$ of fruits per tree) prior to harvest. This alternative allows growers to get rid of the effect of the tree physiological factors and environmental factors on yields, and gives a precise view of the actual orchard yield. In the last decade, many studies have focused on a computer vision systems for fruit detection and counting at the tree scale [6]. These systems combine an image acquisition method using one or several sensors including visible (RGB) cameras [11-13], multispectral/hyperspectral cameras [14], and LiDAR [15,16], with an image processing algorithm. These tools make it possible to accurately count the number of fruits on the tree, albeit with some limitations. Firstly, even with the best algorithm, visual occlusions of fruits hinder the detection of all the fruits on the tree. Consequently, a labor-intensive field calibration is required to estimate the actual tree production (relationship between the image-based fruit count and the actual fruit number in the tree) [12]. Secondly, most developed tools focus on tree scale, with no consideration of yield estimation or extrapolation on the entire orchard. Few state-of-the-art studies estimate orchard yields by means of a mobile platform to track and create a multi-view of all trees in the orchard. For example, Stein et al. [15] used a mobile robot equipped with RGB and LiDAR sensors to map tree production and structure in a commercial orchard. While RGB images are used for multi-view fruit detection, the LiDAR sensor generates an accurate 3D point cloud which is able to 
accurately segment each tree crown. Then, each detected fruit is associated with its corresponding tree. Whereas such tools reach high accuracies for trees production estimation and mapping, they remain expensive and are not applicable to complex orchards (i.e., orchards with random tree arrangement).

Alternatively, to tackle the limitations of tree production estimation by ground remote sensing, one solution is to use above-ground imagery to assess tree features and link them to the yield. Forecasting of orchard yield based on the measurement of vegetation indices and tree crown area by multispectral satellite imagery was tested on mango plantations [17]. However, the results showed low consistency of the relationship between yield and tree features across different orchards, and the method remained dependent on expensive equipment. Several investigations have revealed the advantages of unmanned aerial vehicles (UAVs) for precise land cover and tree architecture mapping in forest stands [18] and orchards [19-21] that could be used for tree production estimations. The miniaturization of sensors, low operation and equipment costs, and high flexibility in time scheduling and avoidance of cloud cover made UAVs appropriate for land cover and yield mapping. Recent studies have used UAVs with RGB sensors [22-24] to accurately estimate tree structure and map orchard land cover through structure-from-motion and photogrammetry [21,22]. Indeed, by flying low with high overlaps, UAVs capture very high resolution (VHR) geotagged images that made it possible to build orthomosaics and digital surface models (DSM) at cm-level resolution. And thanks to this fine spatial resolution (finer than the object of interest), geographic object-based image analysis (GEOBIA) — that has proven to more effectively map land cover than pixel-based algorithms [25] — can be used. GEOBIA also makes it possible to delineate and summarize objects following their spectral, shape, textural, and contextual information. UAVs and GEOBIA procedures have been widely used for tree species classification and delineation, and to characterize tree structure. For example, Torres-Sánchez et al. [20] delineated olive trees with a GEOBIA procedure and accurately quantified tree heights and crown areas and volumes in olive orchards with UAVs. Regarding tree species classification, Michez et al. [26] succeeded in classifying 5 deciduous tree species with a 95\% accuracy rate using a UAV equipped with a hyperspectral sensor. However, land cover mapping and tree structure measurements are often described in separate studies. Few studies have proposed an integrative methodology to estimate both tree species (or cultivars) and structures in complex agro-ecological landscapes such as diversified orchards [27]. Moreover, whereas ground machine vision systems for yield estimation and mapping are effective, the efficiency of UAVs for such purposes has never been tested to our knowledge. Therefore, UAVs might be more interesting than ground machine vision systems due to their covering of the entire orchard, low cost, and high flexibility.

In what follows, we develop a comprehensive set of tools for quantifying the structure of mango trees, and compute orchard land covers in order to accurately estimate and map the production at the orchard scale. The procedure is based on the acquisition of VHR images with a commercial UAV to build an orthomosaic and a DSM of the orchard, upon which a GEOBIA procedure is run to determine tree species and mango cultivars. The produced land cover maps combined with Canopy Height Model (CHM) permitted us to compute tree structure parameters (tree height, crown area, and volume). Using a load index that integrates climate, year, and management effects, and the tree structure parameters as independent variables in tree production models, we mapped the individual mango tree production of the entire orchard. This procedure has been tested and evaluated in fifteen mango orchards of the Niayes region in West Senegal, ranging from family-based, plurispecific orchards, to monocultivar, commercial orchards. This toolbox constitutes a unique, easy-to-use, and useful methodology to semi-automatically map tree production at the orchard scale using UAV photogrammetry and remote sensing. This toolbox stands as a trade-off methodology between complex mechanistic tree production models and labor-intensive empirical measurements of fruit number at the tree level using machine vision systems. 


\section{Materials and Methods}

After a description of the study sites, the following paragraphs describe the workflow for mango yield mapping at the orchard scale (Figure 1).

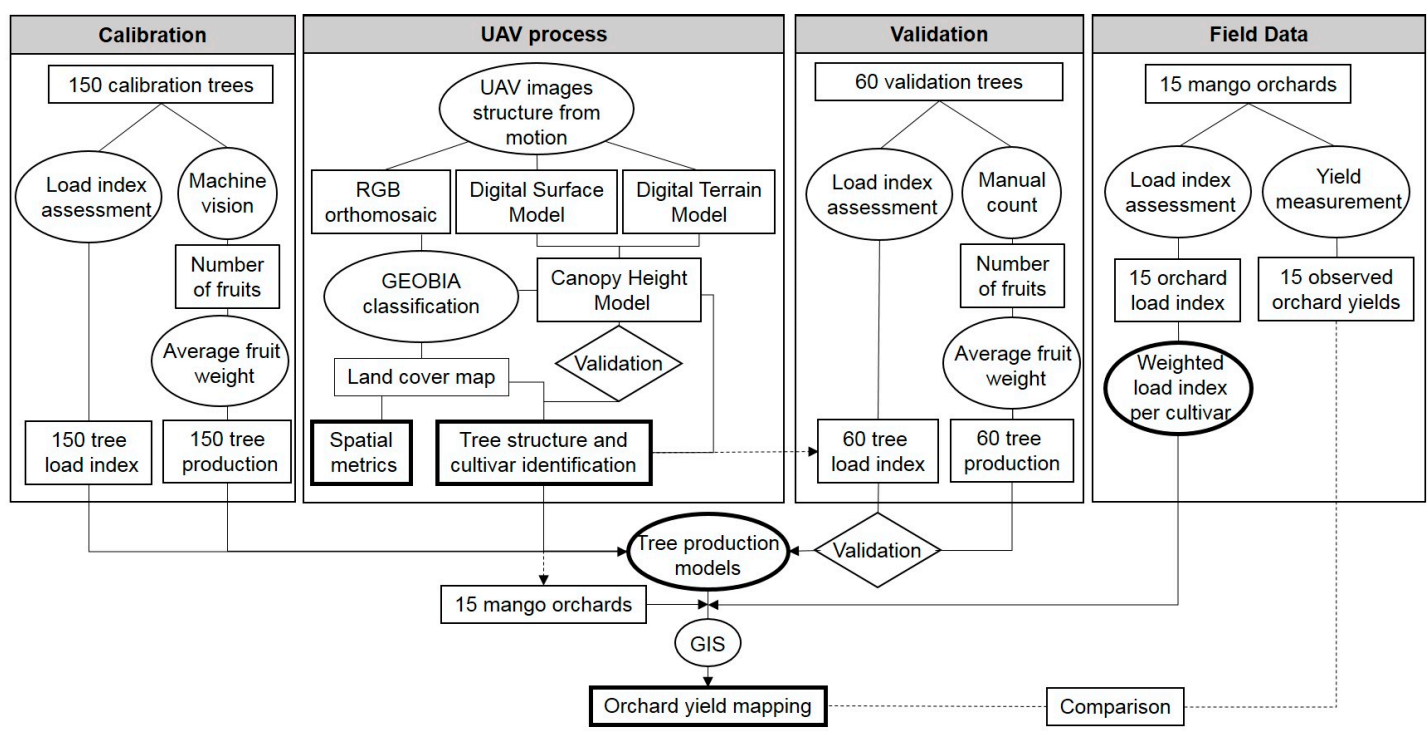

Figure 1. Schematic workflow of the main steps for orchard yield mapping. Each step is fully detailed in Materials and Methods.

\subsection{Study Sites}

The study was carried out in the Niayes region in western Senegal, which represents a major production basin of mangoes for local markets and the first for export markets [4]. The Niayes region is part of the Sudano-Sahelian zone, and is characterized by unimodal rainfall from July to September (mean rainfall of $450 \mathrm{~mm}$ per year) and a relatively fresh and humid climate generated by the proximity to the Atlantic Ocean (with daily mean temperatures ranging from $18{ }^{\circ} \mathrm{C}$ to $30^{\circ} \mathrm{C}$ ). The region is characterized by a succession of dunes with sandy, non-lessive soils and depressions with clay and peaty soils [28]. These topographic depressions-where ground water reaches the surface (shallow sedimentary aquifer retained by impermeable clay deposits)—combined with the climatic conditions make this region the major fruit and vegetable production area in Senegal [28].

Fifteen mango-based orchards (Table 1) have been selected to represent the diversity of cropping systems found in this horticultural area, from small, family-based, diversified orchards, including other tree species (citrus, cashew, etc.) $(n=9)$, to large, commercial-based, monospecific orchards $(n=6)$ [3]. Due to the high diversity of cropping systems, the samples have shown a large variability in mango yields (as estimated by the growers). Indeed, mango yield (expressed in $\mathrm{t} \cdot \mathrm{ha}^{-1}$ ) variability depends both on the orchard design (e.g., tree specific diversity, planting density, and pattern) and agricultural practices which partly drive the orchard production. In our sampling, tree specific diversity ranged from a unique mango cultivar to more than five cultivated tree species and at least four mango cultivars. Additionally, orchard planting pattern and density were highly variable from orchards with continuous in-row canopy to orchards with a random tree arrangement. In 2017, the actual yield of each orchard was asked of the growers. 
Table 1. Description of flight missions and classification for the 15 studied orchards.

\begin{tabular}{|c|c|c|c|c|c|c|}
\hline \multirow{2}{*}{$\#^{1}$} & \multirow{2}{*}{$\begin{array}{c}\text { Flight } \\
\text { Area [ha] }\end{array}$} & \multirow{2}{*}{$\begin{array}{l}\text { Training } \\
\text { Rate [\%] }\end{array}$} & \multicolumn{2}{|c|}{ Number of Class } & \multirow{2}{*}{ Latitude $^{2}$} & \multirow{2}{*}{ Longitude ${ }^{2}$} \\
\hline & & & Level 1 & Level 2 & & \\
\hline 1 & 4.8 & 4.1 & 3 & 1 & $14^{\circ} 49^{\prime} 41^{\prime \prime} \mathrm{N}$ & $17^{\circ} 5^{\prime} 48^{\prime \prime} \mathrm{W}$ \\
\hline 2 & 6.4 & 4.6 & 3 & 1 & $14^{\circ} 59^{\prime} 1^{\prime \prime} \mathrm{N}$ & $17^{\circ} 0^{\prime} 14^{\prime \prime} \mathrm{W}$ \\
\hline 3 & 6.6 & 6.3 & 3 & 1 & $14^{\circ} 59^{\prime} 39^{\prime \prime} \mathrm{N}$ & $16^{\circ} 59^{\prime} 25^{\prime \prime} \mathrm{W}$ \\
\hline 4 & 6.5 & 7.3 & 4 & 1 & $14^{\circ} 49^{\prime} 32^{\prime \prime} \mathrm{N}$ & $17^{\circ} 6^{\prime} 6^{\prime \prime} \mathrm{W}$ \\
\hline 5 & 7.4 & 5.6 & 3 & 3 & $14^{\circ} 47^{\prime} 53^{\prime \prime} \mathrm{N}$ & $17^{\circ} 8^{\prime} 32^{\prime \prime} \mathrm{W}$ \\
\hline 6 & 6.4 & 4.8 & 5 & 3 & $14^{\circ} 48^{\prime} 3^{\prime \prime} \mathrm{N}$ & $17^{\circ} 8^{\prime} 17^{\prime \prime} \mathrm{W}$ \\
\hline 7 & 4.6 & 5.4 & 7 & 2 & $14^{\circ} 47^{\prime} 27^{\prime \prime} \mathrm{N}$ & $17^{\circ} 13^{\prime} 41^{\prime \prime} \mathrm{W}$ \\
\hline 8 & 8.8 & 3.4 & 8 & 2 & $14^{\circ} 48^{\prime} 15^{\prime \prime} \mathrm{N}$ & $17^{\circ} 12^{\prime} 35^{\prime \prime} \mathrm{W}$ \\
\hline 9 & 8.3 & 3.9 & 7 & 3 & $14^{\circ} 46^{\prime} 24^{\prime \prime} \mathrm{N}$ & $17^{\circ} 6^{\prime} 31^{\prime \prime} \mathrm{W}$ \\
\hline 10 & 4.9 & 5.2 & 8 & 3 & $14^{\circ} 45^{\prime} 45^{\prime \prime} \mathrm{N}$ & $17^{\circ} 9^{\prime} 7^{\prime \prime} \mathrm{W}$ \\
\hline 11 & 7.9 & 6.5 & 9 & 2 & $14^{\circ} 49^{\prime} 37^{\prime \prime} \mathrm{N}$ & $17^{\circ} 9^{\prime} 22^{\prime \prime} \mathrm{W}$ \\
\hline 12 & 8.4 & 4.9 & 8 & 3 & $14^{\circ} 50^{\prime} 35^{\prime \prime} \mathrm{N}$ & $17^{\circ} 7^{\prime} 11^{\prime \prime} \mathrm{W}$ \\
\hline 13-14 & 8.2 & 6.6 & 8 & 4 & $14^{\circ} 47^{\prime} 20^{\prime \prime} \mathrm{N}$ & $17^{\circ} 13^{\prime} 36^{\prime \prime} \mathrm{W}$ \\
\hline 15 & 20.5 & 2.5 & 9 & 3 & $14^{\circ} 47^{\prime} 25^{\prime \prime} \mathrm{N}$ & $17^{\circ} 12^{\prime} 18^{\prime \prime} \mathrm{W}$ \\
\hline Mean & 7.8 & 5.0 & & & & \\
\hline
\end{tabular}

\subsection{Production Estimation on Calibration Trees}

In each orchard, ten trees were selected among the three main cultivars found in the study area, i.e., 'Kent', 'Keitt' and 'Boucodiékhal' (BDH), to depict the entire variability of tree structure (trunk perimeter, height, and crown volume), age, and fruit load found in the study area. Thus, this set of 150 mango trees made of 89 ' $\mathrm{Kent}^{\prime}$, 39 'Keitt', and 22 ' $\mathrm{BDH}^{\prime}$ were used to calibrate the predictive models by measuring their production using the machine vision system described below. Then, the representativeness of the calibration trees was tested by comparing their structure assessed by UAV with the structure of all mango trees within the 15 orchards. For this purpose, independent comparisons of means between the two groups were conducted using Student $t$-test at a 95\% confidence level.

During June 2017, the individual tree production from one month to two weeks before harvest was measured on the 150 calibration trees by means of RGB ground image analysis. The machine vision system used for this task is described in Sarron et al. [29]. Briefly, on two opposite pictures of the tree captured with a hand-held Sony Nex-7 RGB camera (Sony Corporation, New York, NY, USA), a pixel k-nearest neighbor $(\mathrm{KNN})$ supervised classification allowed us to detect mango fruits under heterogeneous field conditions. The number of automatically-detected fruits on the images was linked to the actual number of fruits carried by the tree (visually counted in the field on 52 trees) with a robust linear regression for each cultivar. This method has been cross-validated on 52 additional mango trees [29]. The estimated fruit number per tree was then converted into individual production (in $\mathrm{kg}$ ) for the 150 calibration trees using the average fruit weight measured on 90 harvested fruits for each cultivar (Table S1 in Supplementary Materials).

\subsection{Orchard Land Cover Mapping and Tree Structure Assessment Using UAV}

Individual tree detection and classification at the orchard scale were key steps in our workflow to quantify orchard land cover and tree structure (height, crown volume and area), both of which are mandatory to estimate mango yields. The procedure described below consisted of (1) UAV flights for the acquisition of VHR images, (2) generation of orthomosaics and CHM, (3) land cover mapping using advanced GEOBIA; and (4) the extraction and validation of individual tree structures using GIS. 


\subsubsection{UAV System and Flight Missions}

In 2017, the 15 orchards were overflown using a DJI Mavic Pro quadricopter (DJI Inc., Shenzhen, China) equipped with a visual sensor (red, green, and blue-RGB) of 12 megapixels with a focal length of $35 \mathrm{~mm}$. Flight missions were planned using Pix4Dcapture application (Pix4Dcapture 3.2; Pix4D SA, Lausanne, Switzerland) that automatically flew the UAV and triggered the camera to maintain a forward and side overlap of $80 \%$ and $70 \%$ between images, respectively. Images acquired during flights were automatically geotagged using the onboard GPS receiver. The flight height was set to $40 \mathrm{~m}$, resulting in a ground sample distance of $1.30 \mathrm{~cm} \cdot \mathrm{pixel}^{-1}$ [30]. The flight grids covered the entire orchards plus the surrounding landscape, leading to captured areas ranging from 4.6 to 8.8 ha (Table 1). Because of its large area (20.5 ha), orchard \#15 was mapped using two successive flights. Due to the large period of UAV-image acquisition, mango tree phenological stages varied between vegetative growth, flowering, and fruit set.

\subsubsection{Orthomosaics and CHM Generation}

Geotagged VHR images were used to generate RGB orthomosaics and a digital surface model (DSM) of the 15 orchards. Orthomosaics (i.e., a georeferenced aerial image which has been geometrically corrected) of each orchard derived from structure-from-motion image reconstruction using the images acquired during the flight mission [22]. The process was fully automated under Pix4Dmapper Pro software (Pix4Dmapper 1.3; Pix4D SA, Lausanne, Switzerland). We used software parameters that enhanced the accuracy of the orthomosaic and DSM construction: that is, a minimum of two keypoint matches for 3D point setting, a high level of densification of the point cloud, and a sharp DSM filter to preserve the orientation of the surface and to keep sharp 3D features [19]. Following this process, one RGB orthomosaic, one DSM, and one digital terrain model (DTM) were generated for each orchard (UTM coordinates system zone $28 \mathrm{~N}$; datum WGS84). DTM was automatically generated by the software that filtered out non-ground points from the point cloud before a smoothing operation.

As the DSM does not correspond directly to tree height in relation to the ground surface, a Canopy Height Model (CHM) was computed as the subtraction of the DTM from the DSM [23]. Orthomosaic and $\mathrm{CHM}$ of each orchard had a spatial resolution of 1.30 and $6.40 \mathrm{~cm} \cdot \mathrm{pixel}^{-1}$, respectively, and were exported as GeoTIFF files to be further used in remote sensing and in the GIS software.

\subsubsection{Land Cover Mapping Using GEOBIA}

The RGB orthomosaic combined with the CHM produced a four-band, multi-layer image which has been analyzed by a GEOBIA algorithm implemented in eCognition Developer 9 software (Trimble Geospatial, Munich, Germany). The aims of this algorithm were to (1) delineate objects such as individual tree crown, and (2) classify each object to obtain a precise land cover map.

Two segmentations were applied using a multiresolution segmentation algorithm [31], which is a widely-used method for land cover classification from VHR images [19,32]. We applied segmentation on all the four bands (R, G, B, and CHM) with an equal weight for each band [20]. The segmentation scale parameter-i.e., fixing the final size of the objects-and homogeneity criteria (shape and compactness) [26] were adjusted by expert judgment and visual interpretation. Since the orthomosaics covered the entire orchards and the surrounding areas, they showed a variety of object types from small trees or annual crop plots to large buildings (Figure 2a). This heterogeneity led to variability in object size, shape, and spectral signatures. We firstly applied a multiresolution segmentation with a coarse scale parameter of 1000, and homogeneity criterion values of 0.1 and 0.5 , for shape and compactness, respectively. This coarse segmentation allowed us to delineate large and homogeneous objects of buildings and soil that were classified by thresholds on brightness, Excess Green [20], and Excess Red [33] indices. Secondly, a finer multiresolution segmentation was applied to the remaining non-classified objects with a scale parameter of 200 and homogeneity criterion values of 0.1 and 0.5 for shape and compactness, respectively. 
All objects produced by the segmentations were firstly classified (level 1 classification) into ten classes (Table 2) comprising four tree species: "citrus", "mimosae", "cashew" and "mango". This classification included also small heterogeneous "building" and "soil" objects that were not removed by the thresholding after the first segmentation. In order to identify mango cultivars, a second classification (level 2) was applied to classify "mango" objects into 4 cultivar classes: "Kent", "Keitt", "BDH" and "other cultivar". Both classifications used the Random Forest (RF) classifier implemented in eCognition, which is a supervised machine-learning technique that is widely used in the field of remote sensing of agricultural and forest areas using satellite and UAVs [32,34]. For a detailed description of RF functioning, see the review of Belgiu \& Drăguţ [34]. In our case, eCognition was parametrized to use a max Random Tree number of 500 and the number of active variables was set to the square root of the number of features, as recommended in the literature [34,35]. As RF performs better after feature optimization [32], a feature selection was done on one representative orthomosaic. Twenty-one active features were computed for each object: 15 spectral features corresponding to the mean and standard deviation for each of the four bands, brightness, values of hue, saturation, intensity, and Normalized Difference Index (NDI, computed on R and G bands) [11], Excess Green and Excess Red indices; and 6 texture features corresponding to entropy, standard deviation, correlation, mean, homogeneity, and contrast derivatives of Haralick's gray level co-occurrence matrix (GLCM) [36]. Feature selection was performed using a ranking of importance features given by two decision trees in eCognition, i.e., one for each level of classification. Selected features for RF optimization are presented in Table 2.

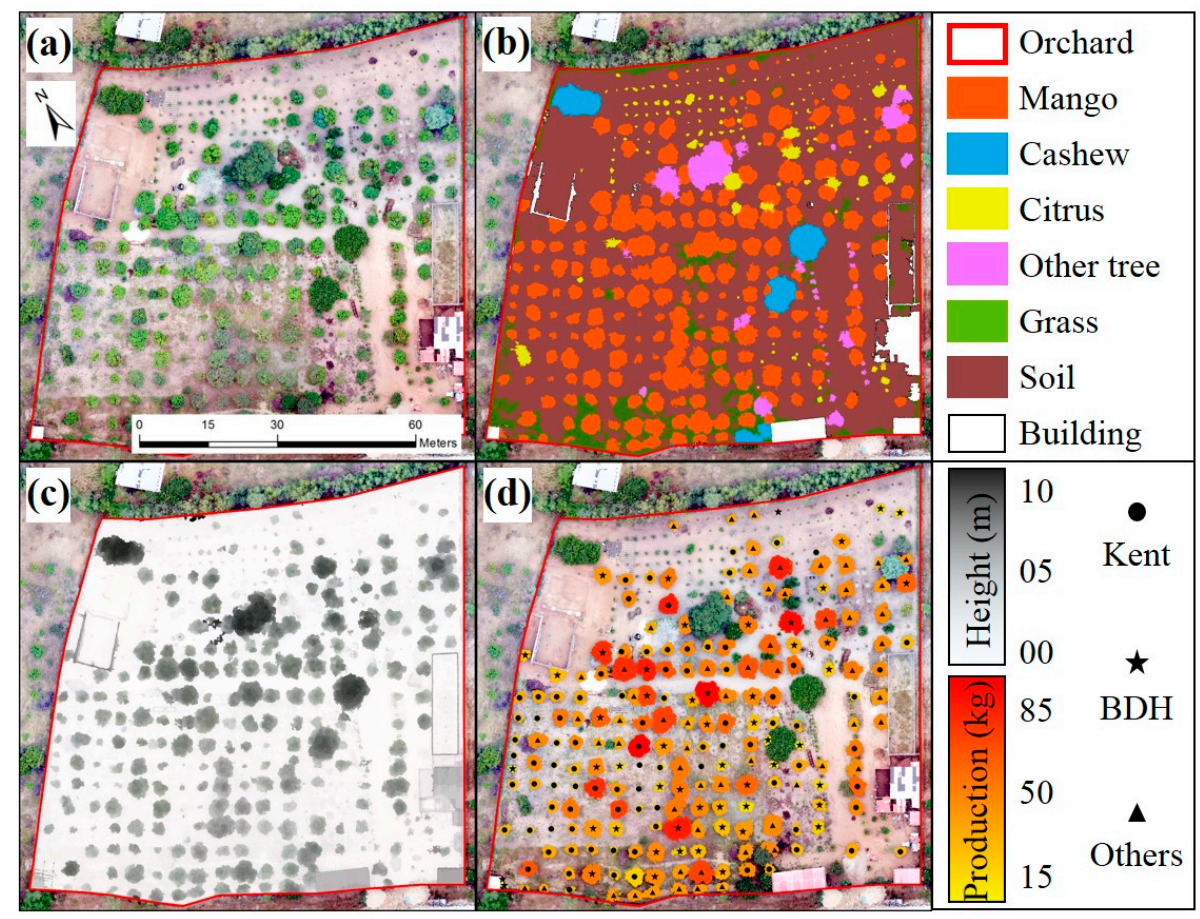

Figure 2. Orchard yield mapping outputs. (a) UAV-acquired RGB orthomosaic; (b) GEOBIA land cover map; (c) Canopy Height Model (in meter); (d) mango cultivar yield map (in kg per tree). UTM coordinates system (zone 28N); Datum WGS84.

Because of variations in mango tree phenological stages between orchards and in environmental conditions during UAV flights, a RF classifier was trained for each classification in each orchard. Training datasets (one for each classification level) were built on manual sample objects selection thanks to the 150 calibration trees, expert photointerpretation, and knowledge of the orchard. For level 1 classification, the training dataset was class-balanced to represent classes' natural proportion, and ranged between $2.5 \%$ and $7.3 \%$ (Table 1 ) of the total number of objects in the orthomosaic 
(Belgiu \& Drăguţ [34] recommended a minimum of 0.25 \% for high accuracy). For level 2 classification, the training dataset was made up of the ten calibration trees completed with few other mango trees for which the cultivar was known. Depending on orchard complexity, the number of classes used varied from 3 to 11 (Table 1).

Finally, the challenging task of tree crown segmentation in complex diversified systems was performed [37]. Indeed, in our procedure, small trees were accurately delineated within one object, whereas large trees were over-segmented and contained several objects. After classification with the GEOBIA algorithm, a post-treatment was needed to delineate tree crowns, as most of them were over-segmented. For this purpose, eCognition "image-object-fusion" and "hierarchical classification" algorithms were applied iteratively to merge objects representing any tree crown objects that have at least $25 \%$ of shared border to another. The super-object was classified using the majority class of it sub-objects. The final land cover map obtained after the GEOBIA process is exemplified in Figure $2 b$.

For each orchard, classification performances (GEOBIA followed by tree crown delineation) were evaluated using 100 randomly-sampled ground control points (GCPs). The actual class of each GCP was manually checked by photointerpretation and compared to the estimated class. Confusion matrices were used to compute overall accuracy (Equation (1)) and the accuracy of the "mango" class (i.e., the fraction of known mango objects correctly classified as mango).

$$
\text { Overall Accuracy }(\%)=100 \times \frac{\text { Number of objects correctly classified }}{\text { Total number of objects }}
$$

Table 2. Classes, spectral and texture features selected for each classification level.

\begin{tabular}{|c|c|c|c|}
\hline $\begin{array}{c}\text { Classification } \\
\text { Level }\end{array}$ & Classes & Spectral Features Selected & Texture Features Selected \\
\hline Level 1 & $\begin{array}{c}\text { soil } \\
\text { building } \\
\text { grass } \\
\text { shrub } \\
\text { annual crop } \\
\text { citrus } \\
\text { mimosae } \\
\text { cashew } \\
\text { mango } \\
\text { other tree }\end{array}$ & $\begin{array}{l}\text { Mean in blue, red and } \mathrm{CHM}^{1} \text {; standard } \\
\text { deviation in blue, green and } \mathrm{CHM}^{1} ; \\
\text { brightness, hue and saturation; } \\
\text { NDI }^{2} \text {, Excess Green and Excess Red }\end{array}$ & $\begin{array}{l}\text { GLCM }^{3} \text { homogeneity, entropy } \\
\text { and standard deviation }\end{array}$ \\
\hline $\begin{array}{c}\text { Level } 2 \\
\text { (mango cultivars) }\end{array}$ & $\begin{array}{c}\text { 'Kent' } \\
\text { 'Keitt' } \\
\text { 'BDH' } \\
\text { other cultivar }\end{array}$ & $\begin{array}{l}\text { Mean in } \mathrm{CHM}^{1} \text { and blue; } \\
\text { standard deviation in blue and green; hue; } \\
\text { Excess Green and Excess Red }\end{array}$ & GLCM $^{3}$ standard deviation \\
\hline
\end{tabular}

${ }^{1}$ Canopy Height Model. ${ }^{2}$ Normalized difference index. ${ }^{3}$ Haralick's gray level co-occurrence matrix.

\subsubsection{Extraction of Individual Tree Structure Parameters Using GIS}

We imported the land cover maps (.shapefile) and the CHM layers (.geotiff) in ArcGIS 10.3 (ESRI, Redlands, CA, USA). All orchard objects were visually checked, and the few tree crowns that were not correctly delineated during the GEOBIA procedure were manually reshaped. Then, we used the "Zonal statistics tool" of the "Spatial analyst extension" of ArcGIS to extract the maximum and sum of the pixel values of the CHM (expressed in meter) encompassed in the area of each mango tree object (Figure 2c). Then, three structure parameters were computed for each individual mango tree: the crown area (in $\mathrm{m}^{2}$ ) obtained directly from the land cover map, tree height (maximum value included in each tree object), and the crown volume (in $\mathrm{m}^{3}$ ) computed as the sum of all CHM pixel values of the object multiplied by the CHM spatial resolution (i.e., $6.40 \times 6.40 \mathrm{~cm}^{2}$ ). For accuracy assessment of tree parameter estimation, the on-ground height of 144 georeferenced trees was made in the field using a ruler. A linear regression was fitted between the measured and UAV-estimated tree 
height. We validated the stability of UAV tree height estimation by computing the root mean square error (RSME) and squared correlation coefficients $\left(\mathrm{R}^{2}\right)$. Relative RMSE (RMSE\%) of validation was calculated as the percentage of the average measured tree height.

\subsection{Model for Individual Tree Yield Estimation}

\subsubsection{Load Index}

Mango tree production (i.e., $\mathrm{kg}$ of fruit per tree) relies on management practices (e.g., irrigation and fertilization regimes) [38] and environmental conditions (e.g., soil, climate) [39], which both vary in time and in space. Furthermore, mango trees display strong reproductive asynchronism and fruiting irregularity within and between the years due to several endogenous and exogenous factors [10]. All these parameters make the task of estimating production from only cultivar and structure information quite challenging. Consequently, we introduced an integrative variable, named "load index", which encompasses management practices, sites, and years related effects. Usually, tree physiologists use fruit load, measured as a ratio between fruit number or biomass and leaves area, to analyze yield. However, fruit load is not easily assessable in the field. In this work, the load index was defined by a qualitative grading of tree bearing by visual inspection in the field: experts qualified the area of visible fruits compared to the visible overall crown area and ranked the tree into "low", "medium", and "high" load index classes. Load index was estimated on the 150 calibration trees simultaneously to image acquisition by at least two experts assisted by image abacus per cultivar (Figure S1 in Supplementary Materials).

\subsubsection{Tree Production Models}

Using the method described above, we characterized the cultivar and quantified structure parameters (tree height, crown area, and volume), load index, and production for the 150 calibration trees. The tree productions showed polynomial distributions against structure variables. We looked for the best predictive model that estimated tree production based on cultivar, load index, and tree structure. For each cultivar, an initial model relating production and the independent variables (i.e., load index factor and structure parameter co-variables) was fitted using a second-degree polynomial regression (squared values of co-variables included). From the initial model, the best predictive model was obtained by a backward elimination which iteratively deleted variables with the highest $p$-value (between 1 and 0.05 ) until only significant variables remained (i.e., $p$-value $<0.05$ ). We fitted one model per cultivar, and an additional model was fitted for other local mango cultivars with the same method by using all trees of the three cultivars for the fittings.

These models have been validated using 60 validation trees on which the actual number of fruits was visually counted in the field by three experts using tally counters. Ground-measured production (in $\mathrm{kg}$ ) was obtained from the conversion of the actual number of fruits using the average fruit weight (Table S1). The stability of production estimation was assessed by computing RMSE and RMSE\% of validation. The significance of the differences between ground-measured and UAV-estimated tree production were tested using a Student $t$-test at a $95 \%$ confidence level.

\subsection{Yield Mapping at the Orchard Scale}

We applied the four production models to estimate mango yields at the orchard scale based on individual tree structure parameters and cultivar, spatially assessed following the workflow described above. In each orchard, the load index per cultivar was visually qualified simultaneously to UAV acquisition on 50 that were trees randomly sampled on a cross transect. The transect passed through the two orchard diagonals, with 25 trees sampled on each, ensuring the spatial distribution of the sampling. As orchard 15 was large (13.8 ha), two transects were performed, resulting in a total of 100 trees sampled. A "null" load index category was given to sampled trees carrying no fruit. Then, the weighted values $a, b, c$, and $d$ of "low", "medium", "high", and "null" load index categories, 
respectively, were computed for each cultivar. Finally, each tree production was averaged using the weighted values of load index as follows (Equation (2)):

$$
P_{k / C}=a P_{k / C, l o w}+b P_{k / C, \text { med }}+c P_{k / C, h i g h}+d \times 0
$$

where $P_{k}$ is the estimated production of tree $\mathrm{k}$ for a given cultivar $\mathrm{C}$ (in $\mathrm{kg}$ ); $a, b, c$, and $d$ are the weighted values for production estimates in "low" $\left(P_{k / C, l o w}\right)$, "medium" $\left(P_{k / C, \text { med }}\right)$, "high" $\left(P_{k / C, h i g h}\right)$, and "null" (considered as $0 \mathrm{~kg}$ ) respectively $(a+b+c+d=1)$. Estimated production was set to 0 when the predictive value given by the model was negative.

As a result, we obtained production for all mango trees in each orchard, and by summing it we calculated mango production (in tons) of the entire orchards. The orchard's productive area (in ha) was determined by delimiting cultivated areas excluding buildings on the land-cover maps. Because each tree was identified in the land cover maps, tree production has been mapped at the orchard scale in ArcGIS (Figure 2d). We investigated for orchard yields assessed by the grower; and measured yield was opposed to the estimated yield. Additionally, the following orchard parameters were computed: estimated yield per hectare (in $\mathrm{t} \cdot \mathrm{ha}^{-1}$ ), mango tree specific area (as a proportion of the total area), mango canopy volume (in $\mathrm{m}^{3} \cdot \mathrm{ha}^{-1}$ ), and mango planting density (number of trees per hectare). Finally, based on the land cover maps, an assessment of the spatial composition was performed using the Simpson diversity index, which represents the probability that two pixels selected at random would be of different object classes [40]. Correlations between these features and orchard yields were studied using Pearson's test.

\section{Results}

\subsection{Accuracy of Classification and Tree Structure Parameters Estimation}

Land cover mapping accuracy of the 15 orchards is described in Table 3. The mean overall accuracy was of 0.89 , and ranged between 0.73 and 0.99 . Despite the fact that no effect of training rate on accuracy was evidenced ( $p$-value $>0.05$ ), an increase in the number of classes significantly decreased the accuracy ( $p$-value < 0.005). Orchards 8, 10, and 13 had accuracies lower than 0.80 . When focusing only on "mango" class accuracy, four orchards $(3,5,7,10$ and 11) reached a score of 1 (Table 3). In these orchards, mango trees are clearly recognizable by their homogeneous crown size compared to other tree species. Only orchard 12 had a "mango" class accuracy lower than 0.80 due to a high level of confusion between mango and citrus trees.

Table 3. Classification accuracy results for the 15 studied orchards.

\begin{tabular}{ccc}
\hline$\#$ & Overall Accuracy & «Mango » Accuracy \\
\hline 1 & 0.98 & 0.96 \\
2 & 0.96 & 0.94 \\
3 & 0.99 & 1.00 \\
4 & 0.96 & 0.86 \\
5 & 0.97 & 1.00 \\
6 & 0.99 & 0.80 \\
7 & 0.88 & 1.00 \\
8 & 0.78 & 0.80 \\
9 & 0.74 & 1.00 \\
10 & 0.85 & 1.00 \\
11 & 0.86 & 0.72 \\
12 & 0.73 & 0.96 \\
$13-14$ & 0.84 & 0.83 \\
15 & 0.87 & 0.89 \\
\hline Mean & 0.89 & 0.91 \\
\hline
\end{tabular}


UAV accuracy for tree height estimation was evaluated by comparing measured and estimated heights (Figure 3). For trees of 1.4 to $8.0 \mathrm{~m}$ in height, the slope of the regression line was 0.77. This suggests that CHM height values slightly underestimated the measured tree heights, especially for trees taller than $5 \mathrm{~m}$. However, estimates were relatively stable ( $\mathrm{R}^{2}$ of 0.96 and RMSE\% reaching $11 \%$ ). We considered these results to be good enough to use the CHM values for tree height and crown volume estimates.

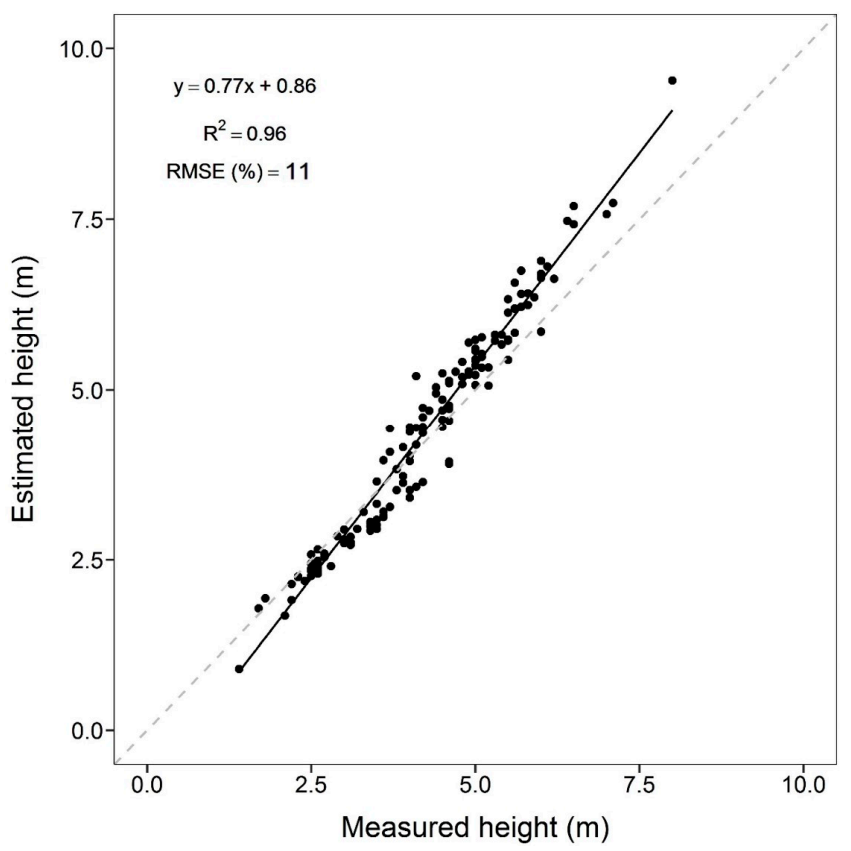

Figure 3. Relationship between the on-ground measured (by ruler) and UAV-estimated (from Canopy Height Model) tree height values for 144 trees. The solid line is the fitted linear function and the dotted line is the 1:1 line.

\subsection{Tree Production Models}

Using a KNN-based machine vision system, we estimated the production of the 150 calibration trees. Furthermore, structure parameters (i.e., tree height, crown area and projected volume) of these trees were extracted from CHM layer. All data of each calibration tree are provided in Table S1. Comparisons of means of tree height, crown area, and volume between the calibration trees and the mango tree population reached $p$-values of $0.07,0.35$, and 0.55 respectively. As all $p$-values were greater than 0.05 , the null $t$-test hypotheses that averages are equals were accepted, and calibration trees were assumed to be representative of mango heterogeneity. Mean production per calibration tree given by machine vision varied from 75 to $183 \mathrm{~kg}$ depending on cultivars (Table 4), and were significantly different following the cultivars ( $p$-value $<0.001)$. These results strengthened our choice to fit different models for each cultivar instead of including a cultivar factor in a global model. The models produced appropriate $\mathrm{R}^{2}$ values of $0.87,0.79,0.87$, and 0.77 for 'Kent', 'Keitt', 'BDH', and other cultivars, respectively (Table 4). In each model, load index was significant, with the highest effect on production (lowest $p$-value $<0.001$ ) compared with tree structure variables. Additionally, all the tree structure parameters were included in 'Kent' and 'Keitt' models, whereas both crown area and tree height had an effect on production for 'other cultivars', and only the crown area was significant in the 'BDH' model.

Models were validated on a set of 60 validation trees not used for fitting the models. The validation set was made of 20 'Kent', 20 'Keitt', and 20 'BDH', and their measured tree production was of $117.35,164.94$, and $155.46 \mathrm{~kg}$ on average, respectively (data not shown). Relationships between ground-measured production and production estimated by each model are displayed in Figure 4, and show no significant difference of means (all $t$-test $p$-value $>0.40$ ). The RMSE\% of validation varied from $19.67 \%$ to $28.83 \%$ (Table 4 and Figure 4 ). Although 'Keitt' and 'other cultivars' models showed 
no misestimation of production in general (Figure $4 \mathrm{~b}, \mathrm{~d}$ ), 'Kent' and 'BDH' models seem to slightly under-estimate production for trees with high production (Figure $4 \mathrm{a}, \mathrm{c}$ ).

Table 4. Tree production models per cultivars built with load index and tree structure parameters; and their respective performances. RMSE and RMSE\% expressed in $\mathrm{kg}$ and \% respectively were computed on 60 validation trees.

\begin{tabular}{|c|c|c|c|c|c|}
\hline \multirow{2}{*}{ Cultivar } & \multirow{2}{*}{ Selected Model $^{1}$} & \multirow{2}{*}{ Mean Production (kg) } & \multirow{2}{*}{$\mathbf{R}^{2}$} & \multicolumn{2}{|c|}{ RMSE } \\
\hline & & & & kg & $\%$ \\
\hline ‘Kent' & $P \sim L I+$ Area + Area $^{2}+$ Vol $^{2}$ & 75.1 & 0.87 & 30.2 & 25.7 \\
\hline ‘Keitt' & $P \sim L I+$ Height + Area + Vol & 182.6 & 0.79 & 32.4 & 19.7 \\
\hline 'BDH' & $P \sim L I+$ Area & 110.8 & 0.87 & 38.3 & 24.6 \\
\hline 'Others' & $P \sim L I+$ Height + Height $^{2}+$ Area + Area $^{2}$ & 104.7 & 0.77 & 42.1 & 28.9 \\
\hline
\end{tabular}

${ }^{1}$ P: tree production (kg); LI: load index; Height, Area and Vol: tree height $(\mathrm{m})$, crown area $\left(\mathrm{m}^{2}\right)$ and crown volume $\left(\mathrm{m}^{3}\right)$, respectively.
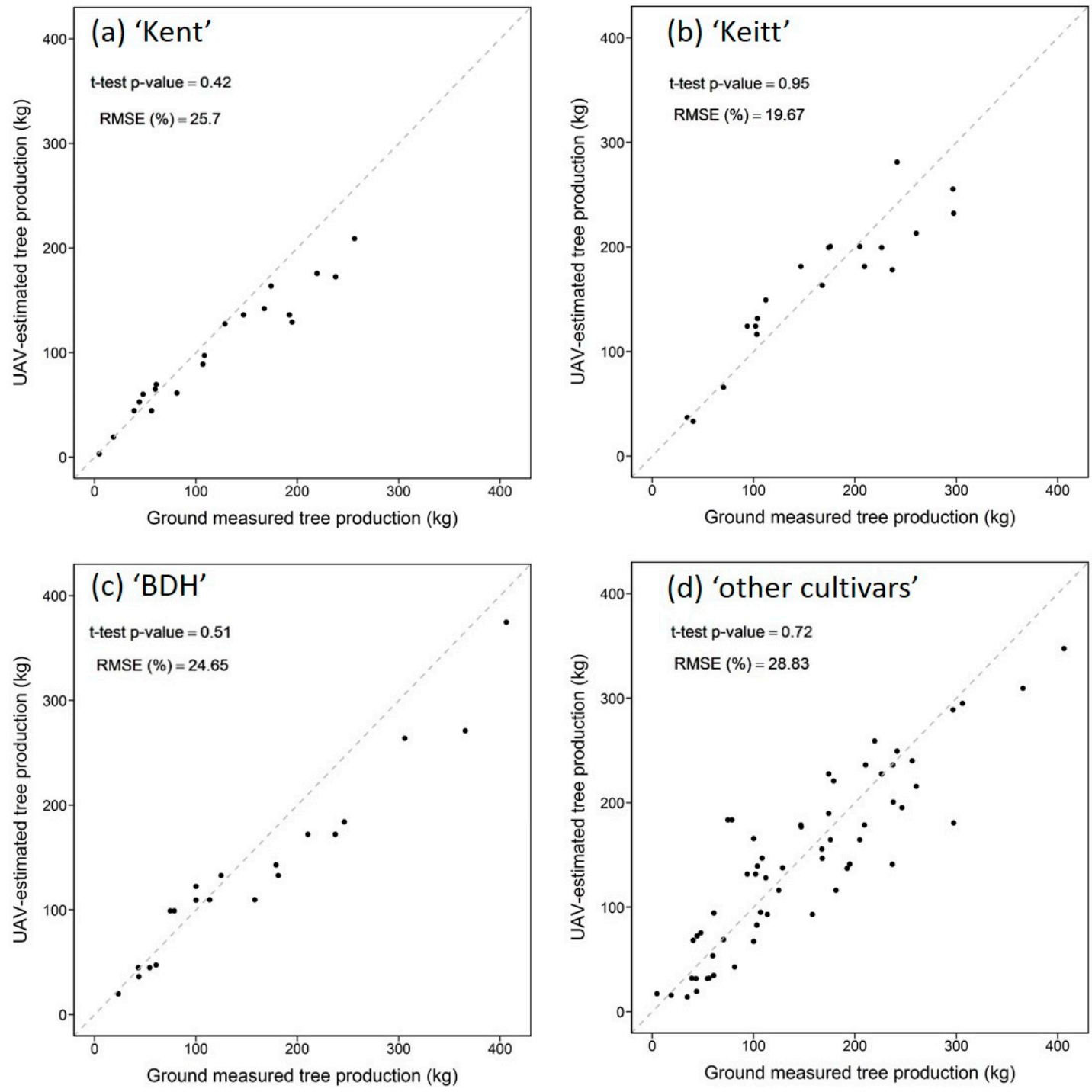

Figure 4. Relationship between the ground-measured tree production and UAV-estimated tree production (a) for 'Kent' trees, (b) for 'Keitt' trees, (c) for 'BDH' trees, and (d) for 'other cultivars' on 60 validation trees. Relative RMSE (RMSE\%) of validation and $p$-value of the $t$-test are displayed on each panel. The dotted line is the 1:1 line. 


\subsection{Yield Estimations}

\subsubsection{Tree Structures and Productions}

In the 15 studied orchards, a total of 5400 mango trees have been identified (cultivars) and described (structures) following the method described above (Figure 5a). The production was estimated on these 5400 trees by applying the models described previously (3.2) and using Equation (2). The number of mango trees per cultivar per orchard was significantly different between orchards (Figure 5a), and the frequency of load index categories depended on the orchard (Chi-squared, $p$-value < 0.001) (Figure 5c). Some orchards $(1,5,10,12,13)$ had high proportions of trees with 'high' and 'medium' load indices, while others $(6,8,9,11)$ had high proportions of 'low' and 'null' indices. Additionally, orchards displayed significant discrepancies in tree structures (Chi-squared, $p$-value $<0.001$ for all tree structure parameters). Some orchards had an average tree height below three meters $(3,4,8)$, and in fact, corresponded to young plantations, while others (10 and 15) displayed a high variability in tree structure (tree heights ranging from $0.5 \mathrm{~m}$ to $16.35 \mathrm{~m}$ ) (Figure $5 \mathrm{~b}$ ).

(a)

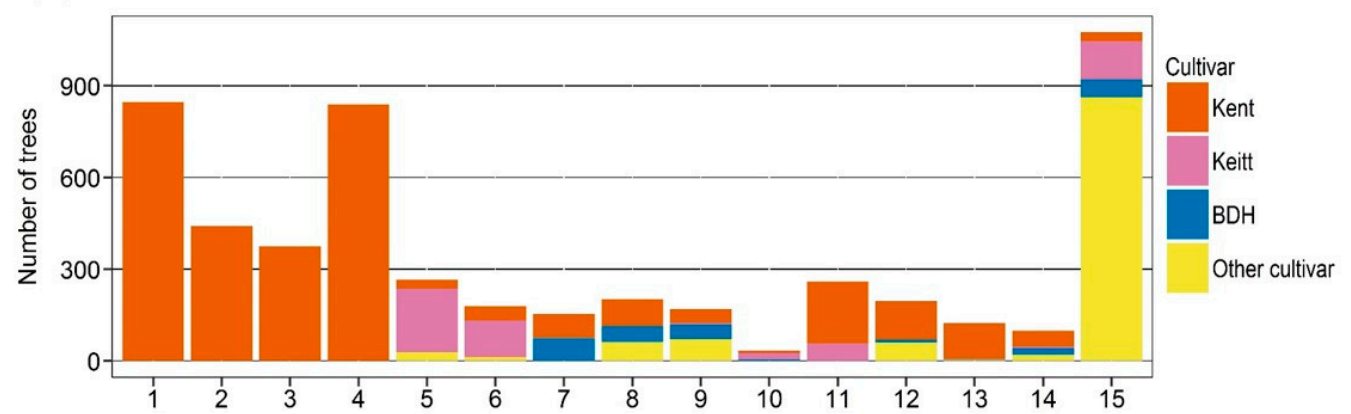

(b)

Orchard

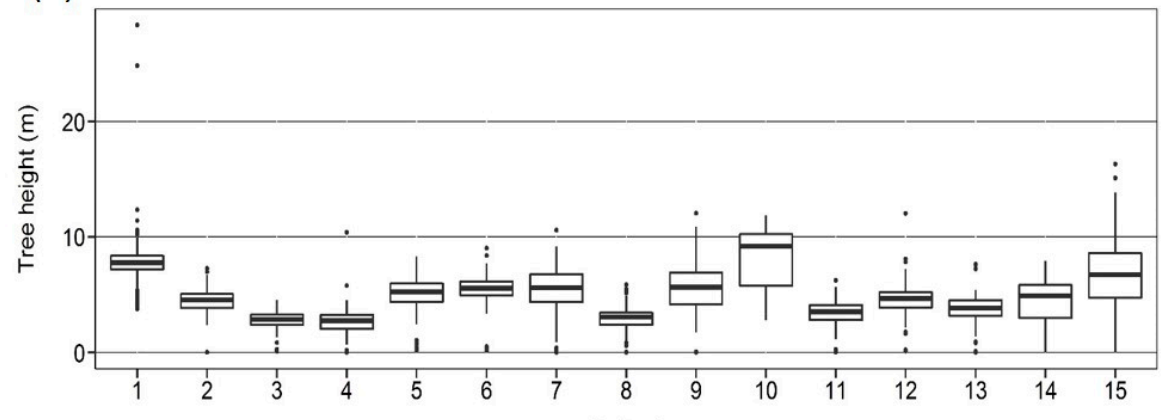

(c)

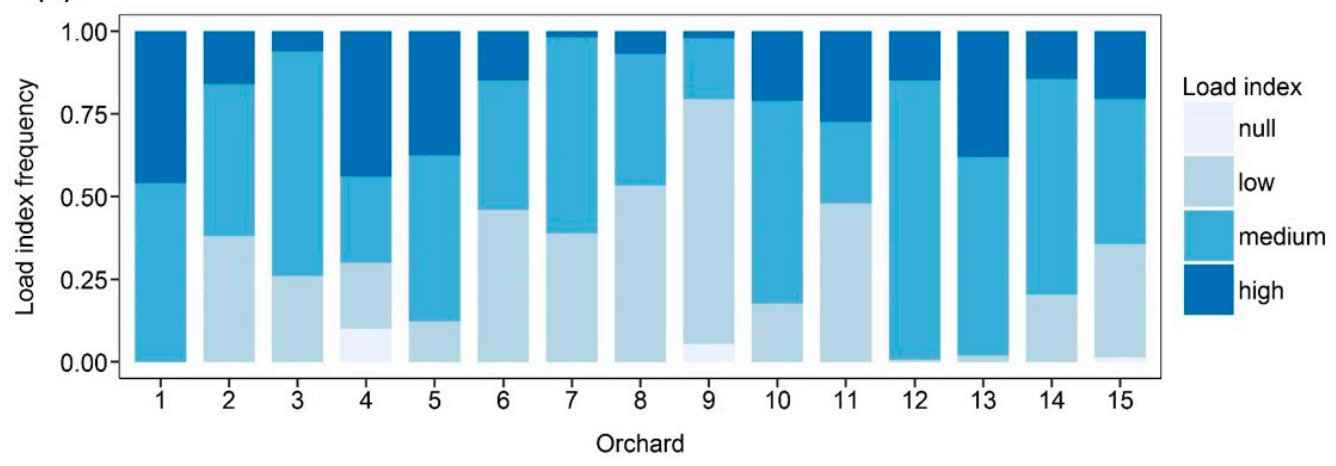

Figure 5. Orchards description: (a) number of trees per cultivar; (b) tree height (m); (c) and frequency of load index.

As a consequence of orchard variations in load index and tree structures, mean tree production varied from $14.6 \mathrm{~kg}$ per tree in orchard 3 to $296.5 \mathrm{~kg}$ per tree in orchard 10. Comparison of these 
two extreme orchards showed that they have the same load indices proportion (Figure $5 c$ ), but that trees have higher structural parameters in orchard 10 than in orchard 3 (Figure 5b).

\subsubsection{Yield Mapping at the Orchard Scale}

Orchard yield was calculated by summing all mango tree estimated productions per productive area (orchard cultivated area in hectare) for each orchard. Those results have been compared to measured yields by the growers in six orchards (data were available). Estimated yields varied from 2.5 to $39.6 \mathrm{t} \cdot \mathrm{ha}^{-1}$ depending on orchards. Estimated yields were consistent with growers' information for orchards 1, 10, and, 11 (Table 5). However, estimations were not aligned with surveyed yields for orchards 2, 3, and 4 (where data reliability was medium or low). Thanks to the GIS software, we mapped individual tree productions in order to visualize orchard yield heterogeneity (see Figure $2 \mathrm{~d}$ for an example). Land cover maps also allowed us to compute some orchard spatial features related to mango trees: planting density (number of mango tree per hectare), mango specific area (\% of area covered by mango), mango canopy volume, and Simpson index (object class diversity). These results are presented in Table 5 .

We found that orchard yield was significantly and positively correlated to planting density, mango specific area, and mango canopy volume with Pearson's correlation coefficients ranging between 0.63 and 0.76 ( $p$-values $<0.05$ ). Cultivar proportion was also found to be an important driver of orchard yields since the four cultivars have significant differences on yield (Table 4). No significant relationship was found between orchard landscape diversity (Simpson index) and yields. Generally, we found that orchard yields were positively linked with planting density and mango canopy volume (correlated to mango specific area), though it was not the case for some orchards, such as orchards 9 and 15. Despite high mango canopy volume in these orchards (more than $20,000 \mathrm{~m}^{3} \cdot \mathrm{ha}^{-1}$ ), their yields were below $5 \mathrm{t} / \mathrm{ha}^{-1}$.

Table 5. Orchard spatial features and yields.

\begin{tabular}{|c|c|c|c|c|c|c|c|}
\hline \multirow{2}{*}{$\#$} & \multirow{2}{*}{$\begin{array}{c}\text { Area } \\
\text { [ha] }\end{array}$} & \multirow{2}{*}{$\begin{array}{l}\text { Planting Density } \\
{\left[\text { tree } \cdot \mathrm{ha}^{-1}\right]}\end{array}$} & \multirow{2}{*}{$\begin{array}{c}\text { Mango Specific } \\
\text { Area [\%] }\end{array}$} & \multirow{2}{*}{$\begin{array}{l}\text { Mango Volume } \\
{\left[\mathrm{m}^{3} \cdot \mathbf{h a}^{-1}\right]}\end{array}$} & \multirow{2}{*}{$\begin{array}{l}\text { Simpson } \\
\text { Index }\end{array}$} & \multicolumn{2}{|c|}{ Orchard Yield $\left[\mathbf{t} \cdot \mathbf{h a}^{-1}\right]$} \\
\hline & & & & & & Estimated & Grower \\
\hline 1 & 2.2 & 386 & 49.7 & 62,792 & 0.51 & 39,619 & $41,079 * * *$ \\
\hline 2 & 2.1 & 214 & 37.9 & 25,878 & 0.47 & 14,627 & $6923 *$ \\
\hline 3 & 2.8 & 138 & 6.0 & 3043 & 0.13 & 2012 & $3667 * *$ \\
\hline 4 & 2.2 & 380 & 13.6 & 5012 & 0.27 & 6737 & $1060 *$ \\
\hline 5 & 3.7 & 72 & 14.9 & 19,513 & 0.25 & 8518 & NA \\
\hline 6 & 1.7 & 107 & 19.4 & 12,131 & 0.35 & 8661 & NA \\
\hline 7 & 1.1 & 169 & 30.6 & 15,511 & 0.70 & 10,400 & NA \\
\hline 8 & 1.1 & 205 & 15.1 & 6019 & 0.56 & 5908 & NA \\
\hline 9 & 2.2 & 86 & 23.1 & 25,624 & 0.73 & 3908 & NA \\
\hline 10 & 1.3 & 25 & 11.2 & 8383 & 0.53 & 7469 & $7634 * * *$ \\
\hline 11 & 1.5 & 172 & 20.0 & 7907 & 0.56 & 11,193 & $10,526^{* * *}$ \\
\hline 12 & 1.2 & 170 & 30.2 & 13,073 & 0.67 & 11,694 & NA \\
\hline 13 & 0.9 & 148 & 16.2 & 4539 & 0.66 & 7867 & NA \\
\hline 14 & 0.9 & 113 & 21.8 & 8924 & 0.47 & 6447 & NA \\
\hline 15 & 13.8 & 80 & 29.0 & 227,040 & 0.56 & 2346 & NA \\
\hline
\end{tabular}

\section{Discussion}

\subsection{Computational Time}

As in [20], computational time is a recognized limit of our work. In the following paragraph, we present the time needed for each step of the presented method when applied on one average-sized orchard (around 2 ha). The computer used for calculation was a Dell Precision M4700 (Dell Inc., Round Rock, TX, USA) with a 16 GB of RAM, an Intel Core i7 processor and a NVIDIA Quadro K1000M graphic card of 2 GB. The first steps of orthomosaic and DSM building took $2 \mathrm{~h} 50$. Duration 
for these steps mainly depended on the covered area and number of images to proceed. Second, most of

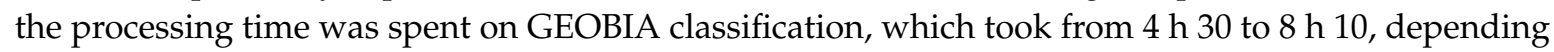
on orchard complexity and whether or not the level 2 classification was applied. Time processing for GEOBIA classification could be summarized as follow: from $1 \mathrm{~h}$ to $2 \mathrm{~h}$ for both segmentation; from $45 \mathrm{~min}$ to $1 \mathrm{~h} 30$ for manual sampling; $20 \mathrm{~min}$ to $1 \mathrm{~h} 00$ for RF training and from $1 \mathrm{~h} 20$ to $4 \mathrm{~h} 40$ for RF application for both classifications. When used, mango cultivar classification added $25 \mathrm{~min}$ to $1 \mathrm{~h} 40$ to the processing time. Finally, RF application took some $20 \%$ of $50 \%$ of the entire processing time, mostly because of the large number of objects to classify (between 38,000 and 580,000 ). To summarize, an average processing time of $15 \mathrm{~h}$ per orchard was needed to apply the presented methodology. Some steps of the procedure required manual operations, and improvement of these steps is discussed in the next paragraph.

\subsection{Challenges of GEOBIA in Heterogeneous Agroecological Landscapes}

To map land cover in each orchard, we used a standard GEOBIA classification process on four-band images (R, G, B, and CHM) acquired by the UAV. Due to their high flexibility, low cost, and the VHR images, UAVs are widely used for the purpose of land cover mapping $[22,26,27]$ and tree crown delineation [19-21,23]. Each of these two tasks requires its own method and algorithm. GEOBIA procedures are recognized to be more accurate than per-pixel classification on complex landscapes [25]. In this work, segmentations allowed us to obtain thousands of objects which were then classified using successively two Random Forest (RF) classifications: a first (level 1) to discriminate mango trees from other tree species or objects (building, grass, etc.); and a second (level 2) applied on mango tree objects to determine their cultivar. These two classifications might be time consuming, as they increase the number of steps. However, as shown by our results, the accuracy of the land cover maps is enhanced by them. Moreover, the spectral and textural similarities between mango and citrus trees and among mango cultivars constrained us to first isolate mango trees and then classify mango cultivars. Such a hierarchical approach significantly improved RF classification accuracy, as shown in previous works [35].

In our study, segment classifications into 10 classes including four tree species ("mango", "citrus", "cashew" and "mimosa") reached an average overall accuracy of $89 \%$ (Table 3). These results confirmed the high efficiency of RF for tree species classification, and were comparable to recent studies on tree species classification in forests. For instance, Nevalainen et al. [27] obtained an accuracy of $95 \%$ for the classification of four tree species in a boreal forest with RF on hyperspectral imagery. Lisein et al. [22] achieved a classification error of $16 \%$ to classify five tree species by using RGB combined with a near infrared (NIR) band. Our results have shown that accuracy decreased when orchard landscapes got more complex (high number of similar classes) and when diversity increased (Simpson index), especially in cases where there were several mango cultivars to discriminate among (Table 3). Visible discrepancies between mango cultivars made level 2 classification possible. However, for some orthomosaics, mango cultivars were not clearly distinct because of flight conditions (high level of shadow or wind) and tree physiological status. To offset this issue, other spectral bands could be added by switching the RGB camera for NIR acquisition or using hyperspectral sensors, as recommended for tree species classification [26,41,42]. In future works, such solutions should be examined, considering that acquisition cost and processing time will increase [18].

Even if feature selection is not imperative to improving RF classification accuracy [32,34], we assume that such a method would decrease computation time by keeping only relevant features. In this work, a decision tree (implemented under eCogition) was applied to rank and select the most important features (Table 2). However, other studies have used more advanced methods, and Ma et al. [32] have compared several methods to determine the most adapted features for RF classifier.

The GEOBIA procedure used in this study was also limited by its semi-automation, mainly during the building of (1) the training dataset and (2) post-processing for tree crown delineation steps. Firstly, 
because UAV images were acquired under different environmental conditions (daytime, luminosity, wind speed, etc.), tree aspect was highly variable between orchards, justifying the use of at least one training dataset per orchard (i.e., 25 training datasets built in total: 15 orchards $x 1$ or 2 classifications). Each training dataset, built by manual sampling of objects in each class, was time consuming and might have led to class imbalance impacting RF classification accuracy [32]. An option could be to transfer a trained RF classifier to another study area, even if the efficiency of such technique remains unclear [43]. Second, due to the high variability of tree structure and plantation patterns within and between orchards, crown delineation was adapted for each situation. Consequently, tree crown delineation ended up being a limiting factor, because for some complex orchards, a step-by-step merging method was used to fuse objects belonging to the same tree crown, and a few crown trees embedded in the same object were manually divided and reshaped. One could think that increasing the scale parameters in multiresolution segmentation or using another segmentation method such as mean-shift segmentation could better delineate trees [41]. However, we deliberately chose to over-segment trees, as classification showed better results, [44] and in order to avoid the non-segmentation of small trees. The delineation of individual trees remains a complex process, especially under heterogeneous, agroecological landscapes, and there are plenty of automatic or semi-automatic algorithms [37] for which efficiency has to be tested in this context. In addition, testing and evaluating new tree crown delineation methods should be completed.

\subsection{Tree Structure Assessment}

The crown volume and area of each tree were computed from Canopy Height Model layer obtained from UAV structure-from-motion process [22]. In our study, the estimated tree height was stable and robust, as RMSE was equal to $0.47 \mathrm{~m}(\mathrm{RMSE} \%=11 \%)$, which was comparable to similar works using RGB cameras. For example, Torres-Sánchez et al. [20] reported errors in tree height assessment ranging from 0.22 to $0.53 \mathrm{~m}$, while Díaz-Varela et al. [19] obtained RMSE $\%$ from $6 \%$ to $20 \%$. Stability in tree height estimations confirmed that UAV-based tree structure parameters can be used as inputs for modelling. However our estimations of tree heights from CHM slightly underestimated measured tree heights (regression slope $=0.77$ ). If exact tree heights were needed, one could calibrate $\mathrm{CHM}$ values using linear regressions fitted in Figure 3. Nevertheless, after the tree structure extraction, we noticed that tree height values were not consistent for only $2.1 \%$ of our trees (low or zero value). These inconsistencies resulted from errors during point cloud densification at DSM construction step. After taking a closer look, we noticed that most of these errors were coming from one orchard (1), which has the highest canopy cover (mango volume $>60000 \mathrm{~m}^{3} \cdot \mathrm{ha}^{-1}$ ) and tree density (386 tree $\cdot \mathrm{ha}^{-1}$ ). Interestingly, previous studies showed that the point cloud generated by structure-from-motion photogrammetry failed to measure the DSM in areas with dense canopy cover [45]. Under such conditions, one should use another source of terrain information such as LiDAR [45]. Another solution could be to adapt the UAV's flight plan in order to enhance 3D triangulation (flight height, grid flight, or viewing angle [46]). Finally, a manual corrective procedure of the point cloud for each misestimated tree might also enhance the accuracy of tree structure assessment.

\subsection{Yield Estimation at the Orchard Scale}

The tols described in this study allowed us to rapidly and precisely map mango yields at the orchard scale across the diversity of mango cropping systems. Quantification of tree species, mango cultivars, estimates of their structure, and load index were implemented as independent variables in models for tree production estimations. These models were fitted to 150 calibration trees depicting the tree structure and fruit load of the three main cultivars ('Kent', 'Keitt' and 'BDH') found in Niayes area. When evaluated with measured production on 60 trees, models reached satisfying accuracies, with $\mathrm{R}^{2}$ greater than 0.77 and RMSE\% of validation ranging from $19.67 \%$ to $28.83 \%$. Few studies used above-ground remote sensing to estimate tree production. For instance, Rahman et al. [17] used multispectral satellite imagery on three mango orchards to compute vegetation indices and tree crown 
area, and linked them to tree production across two years. While their models developed at the individual orchard level for both years reached high efficiencies $\left(R^{2}>0.79\right)$, weaker correlations were obtained by combining data in all orchards $\left(R^{2}=0.70\right)$, or by using a single year $\left(R^{2}<0.57\right)$. Consequently, the correlation between tree production and remotely-assessed features was not generic, and has to be calibrated for each orchard and each year to include climate and site effects. In some previous works, mango yield estimation and, for some, mapping, were achieved by a direct assessment of production of each tree of the orchard by ground machine vision systems composed of a mobile platform (a car or a robot) equipped with GPS and multiple sensors. These studies reach high efficiency for individual tree production estimation, providing accurate yield map of the orchard when performed on all the trees. For example, Payne et al. [47] detected mango fruits by RGB images automatically taken from a car driving down the plantation. The relationship between detected mangoes and the actual tree load was 0.92 . The most advanced system was recently proposed by Stein et al. [15], who used a mobile robot equipped with RGB and LiDAR sensors. This system provided a 3D map of the tree structure and estimated production with an error rate of only $1.36 \%$ compared to validation trees. However, such expensive and time-consuming tools can hardly be employed in complex, diversified orchards and on large areas, which currently represent the majority of the mango cropping systems worldwide, and especially those in developing countries [3,4].

Here, the proposed method achieved the breakthrough of rapidly and precisely mapping mango production without above ground imagery, but rather by linking productions with tree structural parameters. However, the relationship between production and tree crown structure, even measured with the highest precision of a LiDAR, is known to be poor for mango trees, as noticed by Stein et al. [15]. This poor relationship also results from endogenous physiological factors of the tree, as exemplified by Dambreville et al. [10]. By introducing the load index as a proxy of fruit load that is easily measurable at the orchard scale, we solved this issue [17]. We acknowledged that this variable encompassed various effects such as climate, sites, and management practices that could not be estimated in our procedure. Further studies should test the robustness of the tree production models under various conditions (different years and other study areas). As load index is summarized for each cultivar from a transect of 50 trees at the orchard scale, we assumed that tree production was estimated by weighting this variable over the orchard (Equation (2)). We assumed that 50 sampled trees were enough to capture the variability within small orchards (less than 2 ha, the majority in the study area). Moreover, in the study area, large orchards are conventional monospecific systems in which tree structure and production are homogeneous, resulting in a lower sampling intensity needed to capture the orchard variability. Under these conditions, we believe that our sampling methods provide balanced sampling intensity among orchards. Despite this simplification, it was possible to accurately and rapidly map and estimate yield at the orchard scale (Figure 2d). Future works should investigate the effect of the transect method on the accuracy of orchard yield estimation. Additionally, easier sampling and geolocalization of the load index should be explored: this could be done by a visual, ground-based assessment of a given proportion of the trees, or by UAV-based imagery.

Finally, over the 15 studied orchards, production was estimated on 5400 mango trees using the developed models and empirically assessing the load index at the orchard scale. Yields at the orchard scale resulted from the sum of the production of each mango tree of the orchard. Comparisons with growers' information was possible only for 6 orchards, and our estimation was highly accurate for three of them (which had the highest level of reliability). For the other three, differences might be explained by the fact that growers measured their production on plots ( $>10 \mathrm{ha}$ ) larger than our studied area. In these cases, yield measurements by growers are coarse, and do not take into account in-field variations (planting density, tree structure, microclimate, watering heterogeneity, etc.). For instance, the grower of orchard 4 measured production on a plot of $30 \mathrm{ha}$, but admits that yield is closer to $8 \mathrm{t} \cdot \mathrm{ha}^{-1}$ in the 2.21 ha area we studied. Nine out of fifteen orchard growers had no estimation of their actual yields that represent the main case in the studied area, but also, in most of the orchards of developing countries [5]. At best, a manual count of a low number of trees is performed to obtain an 
average number of fruits per tree that is multiplied by the number of trees in the orchard; an estimate that is inaccurate and labor-intensive, and more importantly, that does not inform the grower about the yield distribution within the orchard. To our knowledge, our methodology is the first that allows estimating the orchard yield at tree scale precision by using consumer-grade tools of remote sensing (RGB camera and UAV). We consequently provided a tool for easily quantifying yield heterogeneity and distribution within the orchard; a tool that will inform growers on practices to address the needs of each tree (pruning, watering, etc.) and to plan orchard management (harvest, packing, etc.).

\section{Conclusions}

In this paper, we introduced a new and innovative methodology for yield estimation and mapping at the orchard scale. A set of tools for characterizing and quantifying the structure of mango trees was set up in order to map yields at the orchard scale. The described procedure permitted us to obtain two precise outputs from UAV imagery analysis: (i) a land cover map, and (ii) a Canopy Height Model (CHM). From the latter, three tree structure parameters were computed: tree height, crown area, and crown volume. These variables, combined with a load index, were implemented as independent variables in models for accurate production estimations of each individual tree in the orchard. The procedure is used for yield mapping at the orchard scale. Further works on the GEOBIA classification will make it possible to improve procedure automaticity. By using land cover maps and $\mathrm{CHM}$, other variables describing orchard composition and configuration are computable to explain yield variations. To our knowledge, ours is the first methodology using low-cost tools (RGB camera and UAV) that achieves mapping of tree structures, species, and yield in orchards. This tool addresses the issue of accurate estimates of mango orchard yields, which remains a challenging task, especially in developing countries.

Supplementary Materials: The following are available online at http:/ / www.mdpi.com/2072-4292/10/12/1900/ s1, Figure S1: Image abacus used by expert in the field to estimate load index for (a) 'Kent', (b) 'Keitt', (c) and 'BDH' cultivar. Load index categories (low, medium and high) are displayed in column and different tree heights (small, medium and tall) are represented in line. Table S1: Mean fruit weight and standard deviation (SD) for the three variety in Niayes region. Table S2: Description of the 150 calibration trees: cultivar; number of fruit detected by the KNN-based machine vision and yield measured; load index; and tree structure parameters (tree height, crown area and volume).

Author Contributions: J.S., É.M., and É.F. conceived and designed the experiments; J.S., C.A.B.S., and É.F. performed the experiments; J.S. and É.F. analyzed the data; All authors contributed to the data interpretations and participated in the edition of the manuscript.

Funding: This work was supported by the French National Research Agency under the Investments for the Future Program (ANR-16-CONV-0004) and by the PixYield Creativity and Scientific Innovation action funded by CIRAD, the French agricultural research and international cooperation organization. We received funds for covering the costs to publish in open access.

Acknowledgments: We are grateful to Pierre-Éric Lauri and Frédéric Normand for insightful comments on an earlier version of this work. The authors thank three anonymous reviewers for their valuable comments and constructive suggestions on the manuscript.

Conflicts of Interest: The authors declare no conflict of interest.

\section{References}

1. Mukherjee, S.K.; Litz, R.E. Botany and Importance. In The mango: Botany, Production and Uses; Litz, R.E., Ed.; CABI: Cambridge, MA, USA, 2009; pp. 1-18. ISBN 978-1-84593-489-7.

2. Van Ittersum, M.K.; van Bussel, L.G.J.; Wolf, J.; Grassini, P.; van Wart, J.; Guilpart, N.; Claessens, L.; de Groot, H.; Wiebe, K.; Mason-D'Croz, D.; et al. Can sub-Saharan Africa feed itself? Proc. Natl. Acad. Sci. USA 2016, 113, 14964-14969. [CrossRef] [PubMed]

3. Grechi, I.; Sane, C.A.B.; Diame, L.; De Bon, H.; Benneveau, A.; Michels, T.; Huguenin, V.; Malezieux, E.; Diarra, K.; Rey, J.-Y. Mango-based orchards in Senegal: Diversity of design and management patterns. Fruits 2013, 68, 447-466. [CrossRef] 
4. Rey, J.-Y.; Diallo, T.M.; Vannière, H.; Didier, C.; Kéita, S.; Sangaré, M. The mango in French-speaking West Africa: Varieties and varietal composition of the orchards. Fruits 2007, 62, 57-73. [CrossRef]

5. Carletto, C.; Jolliffe, D.; Banerjee, R. From Tragedy to Renaissance: Improving Agricultural Data for Better Policies. J. Dev. Stud. 2015, 51, 133-148. [CrossRef]

6. Gongal, A.; Amatya, S.; Karkee, M.; Zhang, Q.; Lewis, K. Sensors and systems for fruit detection and localization: A review. Comput. Electron. Agric. 2015, 116, 8-19. [CrossRef]

7. Carletto, C.; Savastano, S.; Zezza, A. Fact or artifact: The impact of measurement errors on the farm size-productivity relationship. J. Dev. Econ. 2013, 103, 254-261. [CrossRef]

8. Van Wart, J.; Kersebaum, K.C.; Peng, S.; Milner, M.; Cassman, K.G. Estimating crop yield potential at regional to national scales. Field Crops Res. 2013, 143, 34-43. [CrossRef]

9. Normand, F.; Lauri, P.-E.; Legave, J.-M. Climate change and its probable effects on mango production and cultivation. Acta Hortic. 2015, 21-31. [CrossRef]

10. Dambreville, A.; Lauri, P.-E.; Trottier, C.; Guedon, Y.; Normand, F. Deciphering structural and temporal interplays during the architectural development of mango trees. J. Exp. Bot. 2013, 64, 2467-2480. [CrossRef] [PubMed]

11. Payne, A.B.; Walsh, K.B.; Subedi, P.P.; Jarvis, D. Estimation of mango crop yield using image analysis-Segmentation method. Comput. Electron. Agric. 2013, 91, 57-64. [CrossRef]

12. Bargoti, S.; Underwood, J. Deep fruit detection in orchards. In Proceedings of the 2017 IEEE International Conference on Robotics and Automation (ICRA), Singapore, 29 May-3 June 2017; pp. 3626-3633.

13. Qureshi, W.S.; Satoh, S.; Dailey, M.N.; Ekpanyapong, M. Dense segmentation of textured fruits in video sequences. In Proceedings of the 2014 International Conference on Computer Vision Theory and Applications (VISAPP), Lisbon, Portugal, 5-8 January 2014; Volume 2, pp. 441-447.

14. Okamoto, H.; Lee, W.S. Green citrus detection using hyperspectral imaging. Comput. Electron. Agric. 2009, 66, 201-208. [CrossRef]

15. Stein, M.; Bargoti, S.; Underwood, J. Image Based Mango Fruit Detection, Localisation and Yield Estimation Using Multiple View Geometry. Sensors 2016, 16, 1915. [CrossRef] [PubMed]

16. Underwood, J.P.; Hung, C.; Whelan, B.; Sukkarieh, S. Mapping almond orchard canopy volume, flowers, fruit and yield using lidar and vision sensors. Comput. Electron. Agric. 2016, 130, 83-96. [CrossRef]

17. Rahman, M.; Robson, A.; Bristow, M. Exploring the Potential of High Resolution WorldView-3 Imagery for Estimating Yield of Mango. Remote Sens. 2018, 10, 1866. [CrossRef]

18. Torresan, C.; Berton, A.; Carotenuto, F.; Di, S.F. Forestry applications of UAVs in Europe: A review. Int. J. Remote Sens. 2017, 38, 2427-2447. [CrossRef]

19. Díaz-Varela, R.A.; de la Rosa, R.; León, L.; Zarco-Tejada, P.J. High-Resolution Airborne UAV Imagery to Assess Olive Tree Crown Parameters Using 3D Photo Reconstruction: Application in Breeding Trials. Remote Sens. 2015, 7, 4213-4232. [CrossRef]

20. Torres-Sánchez, J.; López-Granados, F.; Serrano, N.; Arquero, O.; Peña, J.M. High-Throughput 3-D Monitoring of Agricultural-Tree Plantations with Unmanned Aerial Vehicle (UAV) Technology. PLoS ONE 2015, 10, e0130479. [CrossRef] [PubMed]

21. Jiménez-Brenes, F.M.; López-Granados, F.; de Castro, A.I.; Torres-Sánchez, J.; Serrano, N.; Peña, J.M. Quantifying pruning impacts on olive tree architecture and annual canopy growth by using UAV-based 3D modelling. Plant Methods 2017, 13. [CrossRef] [PubMed]

22. Lisein, J.; Michez, A.; Claessens, H.; Lejeune, P. Discrimination of Deciduous Tree Species from Time Series of Unmanned Aerial System Imagery. PLoS ONE 2015, 10, e0141006. [CrossRef] [PubMed]

23. Birdal, A.C.; Avdan, U.; Türk, T. Estimating tree heights with images from an unmanned aerial vehicle. Geomat. Nat. Hazards Risk 2017, 8, 1144-1156. [CrossRef]

24. Giannetti, F.; Chirici, G.; Gobakken, T.; Næsset, E.; Travaglini, D.; Puliti, S. A new approach with DTM-independent metrics for forest growing stock prediction using UAV photogrammetric data. Remote Sens. Environ. 2018, 213, 195-205. [CrossRef]

25. Blaschke, T. Object based image analysis for remote sensing. ISPRS J. Photogramm. Remote Sens. 2010, 65, 2-16. [CrossRef]

26. Michez, A.; Piégay, H.; Lisein, J.; Claessens, H.; Lejeune, P. Classification of riparian forest species and health condition using multi-temporal and hyperspatial imagery from unmanned aerial system. Environ. Monit. Assess. 2016, 188. [CrossRef] [PubMed] 
27. Nevalainen, O.; Honkavaara, E.; Tuominen, S.; Viljanen, N.; Hakala, T.; Yu, X.; Hyyppä, J.; Saari, H.; Pölönen, I.; Imai, N.N. Individual tree detection and classification with UAV-based photogrammetric point clouds and hyperspectral imaging. Remote Sens. 2017, 9, 185. [CrossRef]

28. Fare, Y.; Dufumier, M.; Loloum, M.; Miss, F.; Pouye, A.; Khastalani, A.; Fall, A. Analysis and Diagnosis of the Agrarian System in the Niayes Region, Northwest Senegal (West Africa). Agriculture 2017, 7, 59. [CrossRef]

29. Sarron, J.; Sané, C.A.B.; Borianne, P.; Malézieux, E.; Nordey, T.; Normand, F.; Diatta, P. Is machine learning efficient for mango yield estimation when used under heterogeneous field conditions? Acta Hortic. 2018, in press.

30. Faye, E.; Rebaudo, F.; Yánez-Cajo, D.; Cauvy-Fraunié, S.; Dangles, O. A toolbox for studying thermal heterogeneity across spatial scales: From unmanned aerial vehicle imagery to landscape metrics. Methods Ecol. Evol. 2016, 7, 437-446. [CrossRef]

31. Baatz, M.; Schäpe, A. Multiresolution Segmentation: an optimization approach for high quality multi-scale image segmentation. In Angewandte Geographische Informationsverarbeitung XII; Strobl, J., Blaschke, T., Griesebner, G., Eds.; Herbert Wichmann Verlag: Karlsruhe, Germany, 2000; pp. 12-23.

32. Ma, L.; Fu, T.; Blaschke, T.; Li, M.; Tiede, D.; Zhou, Z.; Ma, X.; Chen, D. Evaluation of Feature Selection Methods for Object-Based Land Cover Mapping of Unmanned Aerial Vehicle Imagery Using Random Forest and Support Vector Machine Classifiers. ISPRS Int. J. Geo-Inf. 2017, 6, 51. [CrossRef]

33. Meyer, G.E.; Neto, J.C. Verification of color vegetation indices for automated crop imaging applications. Comput. Electron. Agric. 2008, 63, 282-293. [CrossRef]

34. Belgiu, M.; Drăguț, L. Random forest in remote sensing: A review of applications and future directions. ISPRS J. Photogramm. Remote Sens. 2016, 114, 24-31. [CrossRef]

35. Lebourgeois, V.; Dupuy, S.; Vintrou, É.; Ameline, M.; Butler, S.; Bégué, A. A Combined Random Forest and OBIA Classification Scheme for Mapping Smallholder Agriculture at Different Nomenclature Levels Using Multisource Data (Simulated Sentinel-2 Time Series, VHRS and DEM). Remote Sens. 2017, 9, 259. [CrossRef]

36. Haralick, R.M.; Shanmugam, K.; Dinstein, I. Textural Features for Image Classification. IEEE Trans. Syst. Man Cybern. 1973, SMC-3, 610-621. [CrossRef]

37. Ke, Y.; Quackenbush, L.J. A review of methods for automatic individual tree-crown detection and delineation from passive remote sensing. Int. J. Remote Sens. 2011, 32, 4725-4747. [CrossRef]

38. Crane, J.H.; Salazar-Garcia, S.; Lin, T.-S.; de Queiroz Pinto, A.C.; Shü, Z.-H. Crop Production: Management. In The Mango: Botany, Production and Uses; Litz, R.E., Ed.; CABI: Cambridge, MA, USA, 2009; pp. $432-483$. ISBN 978-1-84593-489-7.

39. Davenport, T.L. Reproductive Physiology. In The Mango: Botany, Production and Uses; Litz, R.E., Ed.; CABI: Cambridge, MA, USA, 2009; pp. 97-169. ISBN 978-1-84593-489-7.

40. Lande, R. Statistics and Partitioning of Species Diversity, and Similarity among Multiple Communities. Oikos 1996, 76, 5-13. [CrossRef]

41. Maschler, J.; Atzberger, C.; Immitzer, M. Individual Tree Crown Segmentation and Classification of 13 Tree Species Using Airborne Hyperspectral Data. Remote Sens. 2018, 10, 1218. [CrossRef]

42. Fassnacht, F.E.; Latifi, H.; Stereńczak, K.; Modzelewska, A.; Lefsky, M.; Waser, L.T.; Straub, C.; Ghosh, A. Review of studies on tree species classification from remotely sensed data. Remote Sens. Environ. 2016, 186, 64-87. [CrossRef]

43. Juel, A.; Groom, G.B.; Svenning, J.-C.; Ejrnæs, R. Spatial application of Random Forest models for fine-scale coastal vegetation classification using object based analysis of aerial orthophoto and DEM data. Int. J. Appl. Earth Obs. Geoinf. 2015, 42, 106-114. [CrossRef]

44. Ma, L.; Cheng, L.; Li, M.; Liu, Y.; Ma, X. Training set size, scale, and features in Geographic Object-Based Image Analysis of very high resolution unmanned aerial vehicle imagery. ISPRS J. Photogramm. Remote Sens. 2015, 102, 14-27. [CrossRef]

45. Wallace, L.; Lucieer, A.; Malenovský, Z.; Turner, D.; Vopěnka, P. Assessment of Forest Structure Using Two UAV Techniques: A Comparison of Airborne Laser Scanning and Structure from Motion (SfM) Point Clouds. Forests 2016, 7, 62. [CrossRef] 
46. Zhang, C.; Kovacs, J.M. The application of small unmanned aerial systems for precision agriculture: A review. Precis. Agric. 2012, 13, 693-712. [CrossRef]

47. Payne, A.B.; Walsh, K.B.; Subedi, P.P.; Jarvis, D. Estimating mango crop yield using image analysis using fruit at 'stone hardening' stage and night time imaging. Comput. Electron. Agric. 2014, 100, 160-167. [CrossRef] 